\title{
Breast-feeding counselling mitigates the negative association of domestic violence on exclusive breast-feeding duration in rural Bangladesh. The MINIMat randomized trial
}

\author{
Amy L Frith 1,2,*, Shirin Ziaei ${ }^{2}$, Ruchira Tabassum Naved ${ }^{3}$, Ashraful Islam Khan ${ }^{3}$, \\ lqbal Kabir ${ }^{3}$ and Eva-Charlotte Ekström ${ }^{2}$ \\ ${ }^{1}$ School of Health Sciences and Human Performance, Ithaca College, Ithaca, NY 14850, USA: ${ }^{2}$ International Maternal \\ and Child Health Unit (IMCH), Department of Women's and Children's Health, University Hospital, Uppsala University, \\ Uppsala, Sweden: ${ }^{3}$ International Centre for Diarrhoeal Disease Research, Bangladesh (icddr,b), Dhaka, Bangladesh
}

Submitted 30 September 2016: Final revision received 4 April 2017: Accepted 5 May 2017: First published online 29 June 2017

\begin{abstract}
Objective: To determine if exclusive breast-feeding counselling modifies the association of experience of any lifetime or specific forms of domestic violence (DV) on duration of exclusive breast-feeding (EBF).

Design: In the MINIMat trial pregnant women were randomized to receive either usual health messages (UHM) or usual health messages with breast-feeding counselling (BFC) in eight visits. During pregnancy (30 weeks), lifetime experience of any or specific forms of DV was measured. Infant feeding practice information was collected from 0 to 6 months at $15 \mathrm{~d}$ intervals.

Setting: Matlab, Bangladesh.

Subjects: Pregnant and postpartum women ( $n$ 3186) and their infants.

Results: Among women in the UHM group, those who had experienced any lifetime DV exclusively breast-fed for a shorter duration than women who did not experience any lifetime DV $(P=0 \cdot 02)$. There was no difference, however, in duration of EBF among women in the BFC group based on their experience of any lifetime DV exposure $(P=0 \cdot 48)$. Using Cox regression analysis, there was an interaction of exposure to any lifetime DV, sexual violence and controlling behaviour, and counselling group with duration of breast-feeding at or before 6 months ( $P$-interaction $\leq 0 \cdot 08)$. Among the UHM group, experience of any lifetime DV, sexual violence or controlling behaviour was associated with fewer days of EBF $(P<0 \cdot 05)$. In contrast, among the BFC group, experience of DV was not associated with duration of EBF.

Conclusions: The experience of DV compromises EBF and the support of breastfeeding counselling programmes could assist this vulnerable group towards better infant feeding practices.
\end{abstract}

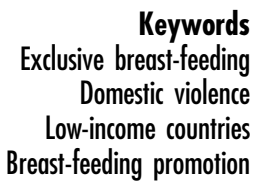

Domestic violence (DV) is a global health and human rights issue. DV includes any act of physical, sexual, emotional abuse and controlling behaviour by an intimate partner or a family member with the intention of inflicting harm or exercising power. In most cases, women are victims and perpetrators are their intimate partners (intimate partner violence (IPV)) $^{(1,2)}$. Globally, one-third of women have experienced physical and/or sexual IPV in their lives ${ }^{(2)}$. DV challenges women through increasing the risk of poorer mental and physical health ${ }^{(3)}$ and through compromising their ability to provide care for children, including feeding ${ }^{(4)}$.
Proper infant feeding practices, particularly exclusively breast-feeding (EBF) for the first 6 months, as recommended by the $\mathrm{WHO}^{(5)}$, are important for child survival, health, growth and development ${ }^{(6-9)}$. While the benefits of EBF for 6 months are known, only $37 \%$ of women in lowand middle-income countries, and even fewer (20\%) in high-income countries, follow these recommendations ${ }^{(8)}$.

Recent attention worldwide on the high prevalence of DV and the harmful consequences for women and children has led to research on the effects of DV on breastfeeding. In past studies, there have been contradictory results regarding the association of exposure to DV and 
duration of $\mathrm{EBF}^{(10-12)}$. In general, however, women who have experienced DV report shorter duration of EBF than those who have not experienced $\mathrm{DV}^{(10-13)}$.

Breast-feeding education and peer counselling extends the duration that women exclusively breast-feed in the general population ${ }^{(14-17)}$. These improvements may be derived from informational and psychosocial support ${ }^{18,19)}$ and by increasing maternal confidence in caregiving and breast-feeding ${ }^{(20)}$. Whether breast-feeding counselling improves the duration of EBF when women have experienced DV is not known.

In Bangladesh, a high proportion of women are exposed to DV in their lifetime ${ }^{(21)}$. Additionally, EBF recommendations are not routinely followed in Bangladesh, with only $37 \%$ of women exclusively breast-feeding when their infants were 5-6 months of age in $2014^{(22)}$. An aim of the present study was to determine if EBF counselling modified the association of experience of any lifetime or specific forms of DV on EBF duration. Another aim was to determine if the experience of any lifetime or the different specific forms of DV (i.e. physical, sexual, emotional, and controlling behaviours) were associated with the duration of EBF.

\section{Methods}

The current study was part of the Maternal and Infant Nutrition Intervention Trial, Matlab (MINIMat; trial registration number ISRCTN16581394) that was conducted in Matlab, a rural sub-district $57 \mathrm{~km}$ south-east of Dhaka, the capital of Bangladesh. The International Centre for Diarrhoeal Disease Research, Bangladesh (known as icddr,b) has been conducting an ongoing health and demographic surveillance in this area since 1966. The MINIMat study compared standard practices utilized by the icddr,b clinics with potentially better practices, such as the usual health counselling $v$. EBF counselling.

\section{Study participants and design}

MINIMat was a population-based food and micronutrient supplementation trial of pregnant women that also included a breast-feeding counselling trial. The study design and procedures have been described in detail previously ${ }^{(23)}$. In brief, during November 2001-October 2003, all women who were identified and confirmed pregnant in the study area were asked to visit icddr,b clinics. If women were less than 14 weeks' pregnant and had no severe illnesses, they were invited to attend the trial. After providing their written informed consent, women were enrolled ( $n$ 4436) and were randomly allocated into one of two types of food supplementation and one of three types of micronutrient supplementation ${ }^{(23)}$. At 30 weeks of gestation, using a computer-generated register that included study identity numbers, participants ( $n$ 3186) were randomized again to receive either the standard ongoing monthly usual health messages (UHM) or the standard ongoing monthly usual health messages with the additional breast-feeding counselling (BFC). The sample size calculation for the main MINIMat study is described by Persson et al. ${ }^{(23)}$. The sample size specifically for the BFC intervention and the present study is described by Khan et $a l .{ }^{(24)}$. The sample size provided the power of 0.90 (type II error) and probability of 0.05 (type I error) to detect a $6 \%$ difference in prevalence of $\mathrm{EBF}$ for the BFC group compared with the UHM group (e.g. 36 v. $30 \%$ ).

\section{Type of counselling}

The icddr,b regular health staff delivered the usual health messages to all women individually during their antenatal clinic visits as is the regular practice in this area. Each woman in the UHM group received infant feeding messages that included the benefits of breast-feeding, colostrum feeding, the initiation of breast-feeding within an hour after birth, the importance of continuing to exclusively breast-feed for up to 6 months and the timely introduction of complementary feeding with continued breast-feeding until their infant reached 2 years of age.

One-on-one breast-feeding counselling (BFC) was provided by trained breast-feeding counsellors, who were women with personal breast-feeding experience, at least 14 years of schooling, willingness to help other mothers breast-feed and were residing in Matlab.

As described by Khan et $a l^{(24)}$, and similar to previous work $^{(15)}$, the strategy to support breast-feeding was a home-based peer counselling approach where the same counsellor visited the mother throughout the sessions. Peer counselling is effective to increase the duration of EBF in Bangladesh ${ }^{(15)}$. A home-based approach was utilized so that counsellors reached those who delivered at home, involved other family members and continued to support breast-feeding postpartum. Peer counsellors were trained using WHO training ${ }^{(25)}$, were paid and supervised by field visits $^{(24)}$. Counselling was a key component of the intervention. Counsellors were trained to provide information regarding benefits of optimal feeding practices, assess the breast-feeding situation through observation and feeding histories, and to counsel. Counselling included listening to the participant, assisting her in deciding what was best for her from various options or suggestions, and then helping her gain the confidence to follow through with her decision $^{(25)}$. Thus, the counsellors were trained to be interactive and supportive to mothers and to include key family members, such as mothers-in-law, by inviting them to participate in the discussions and demonstrations.

The BFC intervention included at least eight visits and began prenatally with two visits in the last trimester of pregnancy (30 and 34 weeks), continued postnatally with one visit from 0 to $7 \mathrm{~d}$ after giving birth, and then five visits monthly between months 1 and 6 in participants' homes. Each visit typically lasted 20 to $40 \mathrm{~min}$. 


\section{Data collection}

Maternal and infant characteristics

Through a household/clinic visit at about week 8 of pregnancy, maternal characteristics including BMI, age, socio-economic status (SES), educational level and household characteristics were recorded by using a precoded questionnaire. SES was calculated from household assets based on composite information about land ownership, characteristics of the household dwelling and household ownership of durables (i.e. bed, quilt, mattress, watch/clock, chair/table, cabinet, bicycle, radio, television, electric fan, cows, goats, chicken/ducks), and divided into quintiles ${ }^{(26)}$. Trained health workers measured and collected information on infant birth characteristics, including sex and birth weight, as described previously ${ }^{(23)}$.

\section{Lifetime experience of domestic violence}

During their clinic visit at week 30, a team of trained paramedics interviewed women regarding their experience of DV by their intimate partner or a family member. Paramedics conducted the interviews in private, as described previously ${ }^{(27)}$. Women who reported physical and sexual violence and suicidal ideation or attempt were offered mental health counselling. A shortened and modified version of Conflict Tactic Scale ${ }^{(28)}$ was used to assess women's experience of lifetime DV. The respondents were asked about their experience of specific acts of physical, sexual, emotional DV and controlling behaviour by their intimate partner or a family member. Based on women's answers to the questionnaire the following binary variables were developed: the experience of any moderate physical DV (yes/no), any severe physical DV (yes/no), any physical (either moderate or severe) DV (yes/no), any sexual DV (yes/no), any emotional DV (yes/no) and any controlling behaviour (yes/no).

Lifetime experience of any DV (yes/no) was defined based on women's experience of one or more acts of violence. The variable 'cumulative number of different forms of DV' was created by summing up different forms of DV (i.e. physical, sexual, emotional, and controlling behaviour) that an individual experienced and categorized as $0=$ none, $1=$ one type, or $2=$ two or more types of DV reported.

\section{Exclusive breast-feeding duration}

When infants were 0-6 months of age, trained female interviewers collected data on infant feeding status at monthly visits with questions pertaining to $15 \mathrm{~d}$ intervals. Questions were asked if the baby had received anything else besides breast milk. The WHO definitions were used for EBF and women were considered to still be exclusively breast-feeding if they were giving only breast milk to the infant, with the exception of oral rehydration solution, liquid medicines and vitamins.

\section{Statistical analyses}

We compared the baseline characteristics of the women and their infants according to whether they had experienced DV or not, and by counselling group. These characteristics were also compared between those who remained in the study and those lost to follow-up. We used $\chi^{2}$ tests for proportions and $t$ tests/ANOVA for means.

Based on the WHO recommendation on the duration of EBF to 6 months, only those who had stopped EBF at or before $180 \mathrm{~d}$ were included in statistical analysis. KaplanMeier survival curves were constructed to describe duration of EBF by exposure to any DV within each counselling group. Kaplan-Meier tests were also used to compare median duration of EBF between counselling groups and determine whether there were differences among those who had experienced DV, and those who had not, in each counselling group. Comparisons were made using log rank tests.

Cox regression analysis was used to evaluate the associations of experiencing any or specific forms of DV and EBF duration separately for each counselling group. Furthermore, the interactions of experience of any or specific forms of DV and counselling groups with EBF duration until 6 months were examined, with $P$ values $<0 \cdot 1$ for interaction terms being considered significant. Food supplementation, micronutrient supplementation, maternal education, SES, BMI, age, parity, and infant sex and birth weight were examined as potential confounders based on past literature and through examining whether they were associated with DV and EBF duration. Food and micronutrient supplementation, maternal age, parity, and infant sex and birth weight were removed from the final models as they were not associated with DV and EBF duration or did not change the model parameters; maternal education, SES and BMI were kept in the models. Statistical analyses were performed with the statistical software package IBM SPSS Statistics version 23.

\section{Results}

Out of the 4436 participants, $3186(71.8 \%)$ of the mothers were randomized to the counselling groups (Fig. 1). There were complete data for 2795 women as others were lost to follow-up or had missing data. Women who were lost to follow-up, or had missing data, were slightly younger (25.36 (SD 5.77) years) than those with complete data (26.33 (SD 5.88) years). They belonged to lower SES groups, had lower education and fewer children. They also had infants with lower birth weight $(2.518$ (SD 0.552$) \mathrm{kg}$ ) compared with women with complete data $(2 \cdot 712$ (SD 0.402$) \mathrm{kg}$ ). The proportions of women who reported having experienced DV were similar between the counselling groups $(57.6 \%$ in UHM and $56.2 \%$ in BFC group; $P>0.05$; data not shown).

No significant differences were observed in maternal and infant characteristics between counselling groups (Table 1). Fifty-seven per cent of women reported that they had experience of any form of violence during 


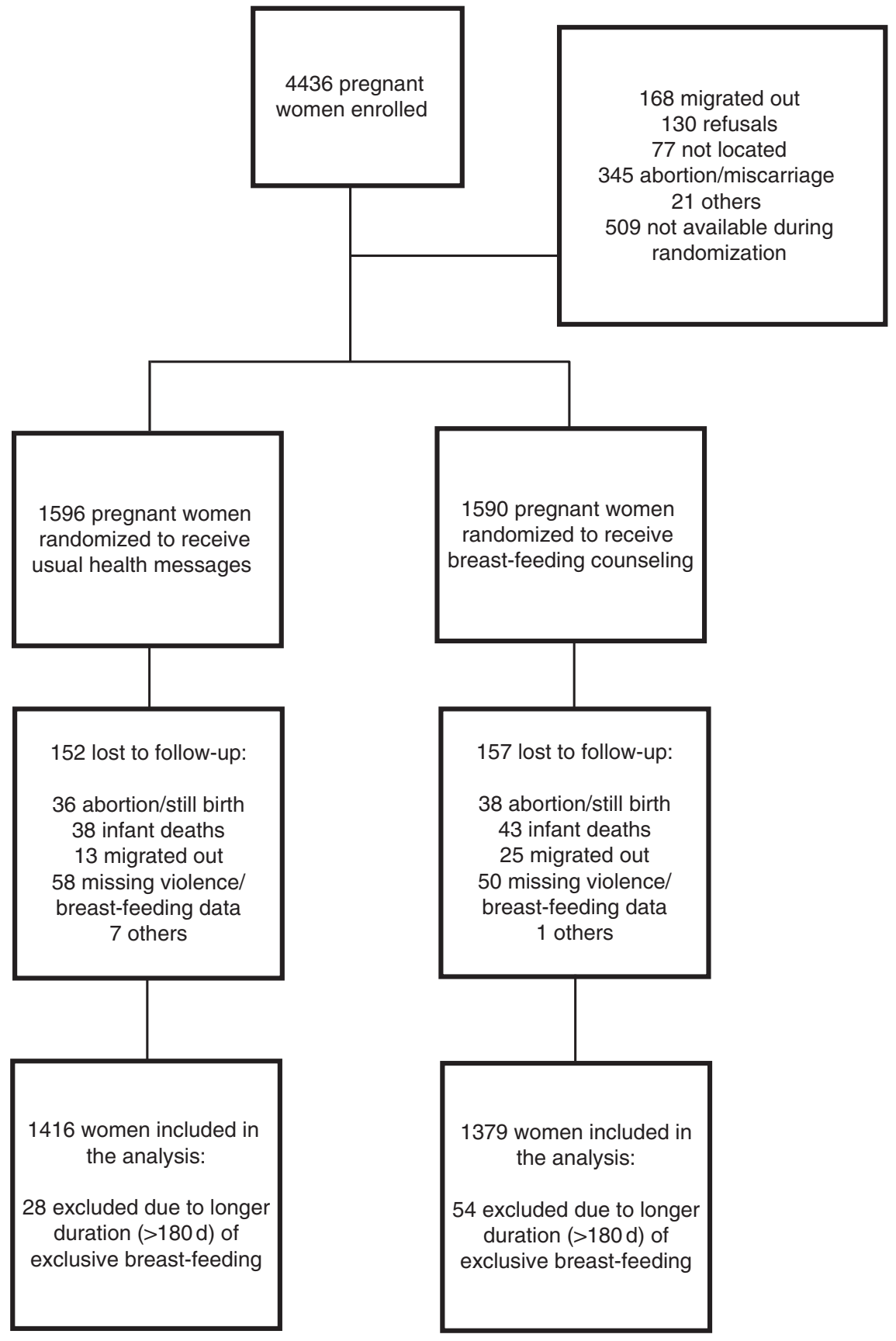

Fig. 1 Flowchart of participating women in Matlab, Bangladesh

their lifetime. The percentage of women who had experienced specific forms of violence was as follows: physical (21\%), sexual (23\%), emotional (28\%) and controlling behaviour (37\%). Twenty-six per cent of women experienced one form of DV, and $31 \%$ experienced two or more forms of DV (data not shown). Women who experienced violence had lower BMI and education, a greater proportion were in the lower SES category and more likely to have more children, and their infants had lower birth weight (Table 1).

Median duration of EBF was $105 \mathrm{~d}$ for the study sample, and women in the BFC group breast-fed for $75 \mathrm{~d}$ longer than women in the UHM group (135 v. $60 \mathrm{~d}$, respectively; $P<0 \cdot 01$; data not shown).

Statistical analysis using the Kaplan-Meier tests confirmed the results from the visual examination of Fig. 2. Women who experienced any lifetime DV and had no breast-feeding counselling had the shortest duration of $\mathrm{EBF}$. In the UHM group, the experience of any DV was associated with up to thirty fewer days of $\mathrm{EBF}(P=0 \cdot 02$; Table 2). Additionally, the experience of sexual DV $(P=0.02)$ and controlling behaviour $(P=0.06)$ reduced median duration of $\mathrm{EBF}$ by $15 \mathrm{~d}$. In the $\mathrm{BFC}$ group, the experience of any of the forms of DV did not reduce 
Table 1 Maternal and infant characteristics by counselling group and women's experience of any lifetime domestic violence (DV) in Matlab, Bangladesh

\begin{tabular}{|c|c|c|c|c|c|c|c|c|c|c|c|c|}
\hline \multirow[b]{3}{*}{ Variable } & \multicolumn{5}{|c|}{ Counselling group } & \multicolumn{5}{|c|}{ Women's experience of any lifetime DV } & & \\
\hline & \multicolumn{2}{|c|}{$\underset{(n 1416)}{\mathrm{UHM}}$} & \multicolumn{2}{|c|}{$\begin{array}{c}\text { BFC } \\
(n 1379)\end{array}$} & \multirow[b]{2}{*}{$\begin{array}{c}P \\
\text { value† }\end{array}$} & \multicolumn{2}{|c|}{$\begin{array}{c}\text { No DV } \\
(n \text { 1202) }\end{array}$} & \multicolumn{2}{|c|}{$\begin{array}{l}\text { Any DV } \\
(n \text { 1593) }\end{array}$} & \multirow[b]{2}{*}{$\begin{array}{c}P \\
\text { value }\end{array}$} & \multicolumn{2}{|c|}{$\begin{array}{c}\text { Total } \\
(n \text { 2795)§ }\end{array}$} \\
\hline & $\begin{array}{c}\text { Mean or } \\
n / N\end{array}$ & $\begin{array}{l}\text { SD or } \\
\%\end{array}$ & $\begin{array}{c}\text { Mean or } \\
n / N\end{array}$ & $\begin{array}{l}\text { SD or } \\
\%\end{array}$ & & $\begin{array}{c}\text { Mean or } \\
n / N\end{array}$ & $\begin{array}{l}\text { SD or } \\
\%\end{array}$ & $\begin{array}{c}\text { Mean or } \\
n / N\end{array}$ & $\begin{array}{l}\text { SD or } \\
\%\end{array}$ & & $\begin{array}{l}\text { Mean or } \\
n / N\end{array}$ & $\begin{array}{l}\text { SD or } \\
\%\end{array}$ \\
\hline Age (years) & $26 \cdot 24$ & $5 \cdot 76$ & $26 \cdot 42$ & 5.92 & 0.41 & $26 \cdot 11$ & 5.78 & $26 \cdot 50$ & 5.94 & 0.08 & $26 \cdot 33$ & $5 \cdot 88$ \\
\hline & 2.53 \\
\hline Lowest & $263 / 1416$ & 18.6 & 269/1379 & 19.5 & 0.49 & $193 / 1202$ & $16 \cdot 1$ & $339 / 1593$ & 19.0 & $<0.01$ & $532 / 2795$ & $19 \cdot 0$ \\
\hline Low & $277 / 1416$ & $19 \cdot 6$ & $285 / 1379$ & 20.7 & & $224 / 1202$ & $18 \cdot 6$ & $338 / 1593$ & $20 \cdot 1$ & & $562 / 2795$ & $20 \cdot 1$ \\
\hline Middle & $274 / 1416$ & 19.4 & $283 / 1379$ & 20.5 & & $222 / 1202$ & 18.5 & $335 / 1593$ & 19.9 & & $557 / 2795$ & 19.9 \\
\hline High & $289 / 1416$ & $20 \cdot 4$ & $271 / 1379$ & $19 \cdot 7$ & & $258 / 1202$ & 21.5 & $302 / 1593$ & $20 \cdot 0$ & & $560 / 2795$ & $20 \cdot 0$ \\
\hline Highest & $323 / 1416$ & $22 \cdot 1$ & $271 / 1379$ & $19 \cdot 7$ & & $305 / 1202$ & $25 \cdot 4$ & $279 / 1593$ & $20 \cdot 9$ & & $584 / 2795$ & 20.9 \\
\hline \multicolumn{13}{|l|}{ Education } \\
\hline None & $425 / 1416$ & $30 \cdot 0$ & $421 / 1379$ & $30 \cdot 5$ & 0.95 & $333 / 1202$ & $27 \cdot 7$ & $513 / 1593$ & $32 \cdot 2$ & $<0.01$ & $846 / 2795$ & $30 \cdot 3$ \\
\hline $1-5$ years & $318 / 1416$ & 22.5 & $305 / 1379$ & $22 \cdot 1$ & & $243 / 1202$ & $20 \cdot 2$ & $380 / 1593$ & 23.9 & & $623 / 2795$ & $22 \cdot 3$ \\
\hline$\geq 6$ years & $673 / 1416$ & 47.5 & $653 / 1379$ & 47.4 & & $626 / 1202$ & $52 \cdot 1$ & $700 / 1593$ & 43.9 & & $1326 / 2795$ & 47.4 \\
\hline \multicolumn{13}{|l|}{ Parity } \\
\hline 0 & $455 / 1414$ & $32 \cdot 2$ & $455 / 1378$ & 33.0 & 0.21 & $432 / 1202$ & 35.9 & $478 / 1590$ & $30 \cdot 1$ & $<0.01$ & $910 / 2792$ & $32 \cdot 6$ \\
\hline 1 & $428 / 1414$ & $30 \cdot 3$ & $380 / 1378$ & $27 \cdot 6$ & & $344 / 1202$ & $28 \cdot 6$ & $464 / 1590$ & 29.2 & & $808 / 2792$ & 28.9 \\
\hline 2 & $290 / 1414$ & 20.5 & $283 / 1378$ & 20.5 & & $240 / 1202$ & $20 \cdot 0$ & $333 / 1590$ & $20 \cdot 9$ & & $573 / 2792$ & 20.5 \\
\hline 3 & $131 / 1414$ & $9 \cdot 3$ & $160 / 1378$ & 11.6 & & 110/1202 & $9 \cdot 2$ & $181 / 1590$ & 11.4 & & 291/2792 & 10.5 \\
\hline$\geq 4$ & $110 / 1414$ & $7 \cdot 8$ & $100 / 1378$ & $7 \cdot 3$ & & $76 / 1202$ & $6 \cdot 3$ & $134 / 1590$ & 8.4 & & 210/2792 & 7.5 \\
\hline \multicolumn{13}{|c|}{ Sex of the child } \\
\hline Female & $684 / 1407$ & $51 \cdot 4$ & $655 / 1371$ & $52 \cdot 2$ & 0.68 & $574 / 1193$ & 51.9 & $765 / 1585$ & $51 \cdot 7$ & 0.48 & $1339 / 2778$ & $48 \cdot 2$ \\
\hline Male & $723 / 1407$ & 48.6 & $716 / 1371$ & 47.8 & & $619 / 1193$ & $48 \cdot 1$ & $820 / 1585$ & $48 \cdot 3$ & & $1439 / 2778$ & 51.8 \\
\hline $\begin{array}{l}\text { Child's birth } \\
\text { weight }(\mathrm{g})\end{array}$ & $2711 \cdot 72$ & $400 \cdot 24$ & $2712 \cdot 62$ & $403 \cdot 34$ & 0.95 & $2733 \cdot 19$ & $403 \cdot 41$ & $2696 \cdot 36$ & 399.82 & 0.02 & $2712 \cdot 16$ & $401 \cdot 70$ \\
\hline
\end{tabular}

UHM, usual health message; BFC, breast-feeding counselling; SES, socio-economic status.

†Comparison between women, based on counselling group. $P$ values calculated from $t$ tests/ANOVA for continuous variables and $\chi^{2}$ test for categorical variables.

¥Comparison between women, based on lifetime experience of any DV. $P$ values calculated from $t$ tests/ANOVA for continuous variables and $\chi^{2}$ test for categorical variables.

$\S$ Total sample size varies due to missing values.

median duration of EBF (Table 2). In both counselling groups, severity of physical DV and the number of forms of DV were not associated with median duration of EBF ( $P>0.05$; data not shown).

In adjusted Cox regression models, the hazards ratio for early cessation of EBF was higher in those who were exposed to any DV, sexual DV $(P<0.05)$ and tended to be higher in those who had experienced controlling behaviour $(P=0.08)$ if women were in the UHM group (Table 3). However, there was no association of exposure to lifetime experience of any or specific DV and duration of EBF if women were in the BFC group. In addition, there was an interaction of the exposure to any DV, sexual DV and controlling behaviour, and counselling group with EBF duration $(P \leq 0 \cdot 08)$.

\section{Discussion}

A high proportion of women in this population experienced some form of DV in their lifetime (57\%). DV impinged on the ability to exclusively breast-feed within the recommended 6-month period in women who received only the usual health messages. One-on-one breast-feeding counselling, however, mitigated the negative association of DV on duration of EBF.

In our study, women who were exposed to any lifetime or sexual DV had reduced days of EBF in the UHM group. DV could influence breast-feeding through increasing infant irritability due to exposure to maternal stress in pregnancy, as well as reducing the mother's ability to care for the infant due to increased psychological (e.g. depression), behavioural (e.g. lack of seeking health care), physical (e.g. injury) and nutritional (e.g. malnourishment) challenges ${ }^{(4)}$. Consistent with our finding, in national surveys from Liberia, Ghana and Kenya, maternal experience of lifetime sexual or emotional IPV reduced the duration of EBF for infants less than 6 months old ${ }^{(10)}$. Consistent with these results, in India, experience of any lifetime, physical or sexual IPV was associated with fewer women exclusively breast-feeding their infants until 6 months ${ }^{(12)}$. Furthermore, in a recent survey from Norway, women who were exposed to emotional, sexual or physical abuse as adults were more likely to stop breast-feeding before 4 months ${ }^{(13)}$. Contrary to these findings, in Tanzania and Zambia, women exposed to physical or sexual IPV exclusively breast-fed for longer ${ }^{(10)}$. An explanation proposed by Misch et al. ${ }^{(10)}$ is that, 
in some contexts, mothers may exhibit compensatory responses when victimized by IPV, such that they may be more sensitive to the needs of their child and show more positive parenting behaviours, including longer duration of EBF. Although DV generally shortens the time mothers breast-feed exclusively, there is no clear explanation as to why the form of DV that is associated with breast-feeding differs among countries, but may be due to measurement, context or individual factors. As suggested by Misch et al. ${ }^{(10)}$, cross-cultural longitudinal research is needed to clarify both the mediators of DV on breast-feeding (i.e. lack of prenatal

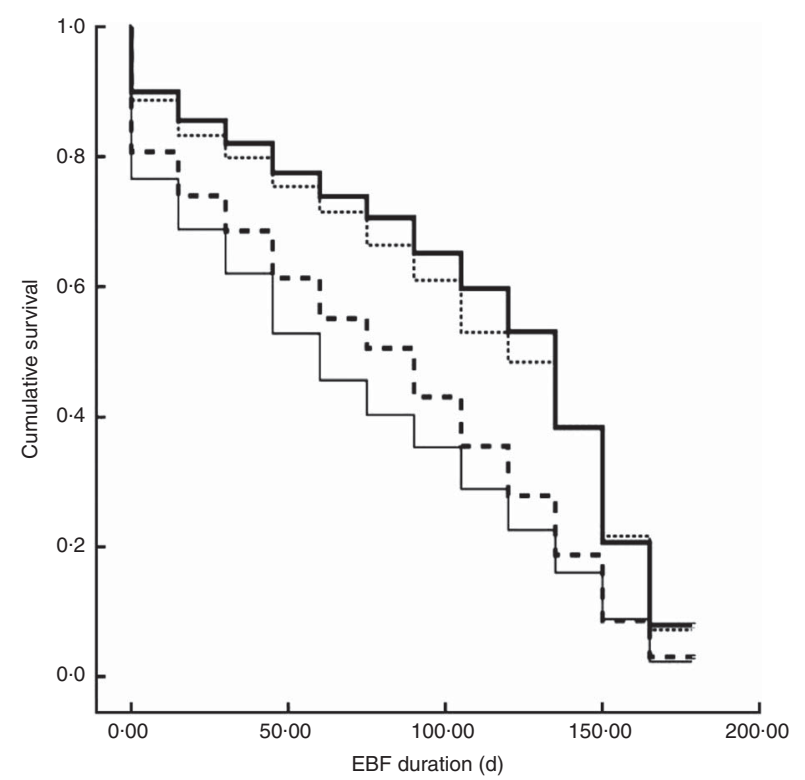

Fig. 2 Survival curves of duration of exclusive breast-feeding (EBF) until 6 months, based on women's experience of any lifetime domestic violence (DV) and counselling group (UHM, usual health message; BFC, breast-feeding counselling) in Matlab, Bangladesh: ----, UHM/no experience of any DV; - UHM/with experience of any DV; ..........., BFC/no experience of any DV; — , BFC/with experience of any DV care, depression, substance abuse) and the contextual variations that could explain differences in the association of DV and breast-feeding (e.g. quality of prenatal care, beliefs about breast-feeding and the health efforts to promote breast-feeding).

The current study adds to the literature on determinants of EBF by demonstrating specifically that controlling behaviour is associated with shorter duration of EBF. Controlling behaviour is one of the most common forms of violence $^{(29,30)}$ and includes restricting women's access to social and emotional resources. Controlling behaviour can also limit women's ability to control their health-behaviour decision making and their access to health care ${ }^{(2,31)}$; therefore, screening and prevention of controlling behaviour should be considered in promoting women's and children's health.

The present study also contributes to the literature by examining the number of forms of DV experienced and the relationship to EBF duration. Exposure to many forms of DV increases both the risk to and the extent of damage to a woman's health ${ }^{(32-34)}$. In our study, whether women had experienced one, or more than one forms of DV, they had equally shorter durations of EBF. It is possible that DV has a low threshold effect on EBF duration, such that any experience with DV negatively impacts this breast-feeding practice.

As shown previously ${ }^{(24)}$, the one-on-one breast-feeding counselling increased median duration of EBF. This counselling may increase the duration of EBF through providing knowledge, support, efficacy and psychosocial support $^{(35-37)}$. In a recent study in rural Bangladesh ${ }^{(20)}$, it was demonstrated that breast-feeding counselling provides women with increased knowledge, support and efficacy (i.e. the belief that one can do a specific task ${ }^{(38)}$ ). The training and intervention in the current study emphasized the interactive character of the sessions, including providing knowledge, support and confidence building. Together with the continuity of contact between

Table 2 Median duration (d) of exclusive breast-feeding based on women's experience of domestic violence (DV) and counselling group in Matlab, Bangladesh†

\begin{tabular}{|c|c|c|c|c|c|c|}
\hline \multirow[b]{3}{*}{ Women's experience of DV } & \multicolumn{6}{|c|}{ Counselling group } \\
\hline & \multicolumn{2}{|c|}{ UHM $(n 1416)$} & \multirow[b]{2}{*}{$P$ value $\ddagger$} & \multicolumn{2}{|c|}{$\mathrm{BFC}(n$ 1379) } & \multirow[b]{2}{*}{$P$ valuef } \\
\hline & Median & $95 \% \mathrm{Cl}$ & & Median & $95 \% \mathrm{Cl}$ & \\
\hline \multicolumn{7}{|l|}{ Experience of any lifetime DV } \\
\hline No $(n$ 1202) & $90 \cdot 00$ & $80.02,99.98$ & \multirow[t]{2}{*}{0.02} & $120 \cdot 00$ & $112.05,127.95$ & \multirow[t]{2}{*}{0.48} \\
\hline Yes $(n 1593)$ & 60.00 & $52.96,67.04$ & & 135.00 & $130.16,139.84$ & \\
\hline \multicolumn{7}{|l|}{ Experience of any sexual DV } \\
\hline No $(n 2156)$ & $75 \cdot 00$ & $67 \cdot 50,82 \cdot 50$ & \multirow[t]{2}{*}{0.02} & $135 \cdot 00$ & $129.96,140.04$ & \multirow[t]{2}{*}{0.95} \\
\hline Yes (n 639) & $60 \cdot 00$ & $51 \cdot 27,68 \cdot 73$ & & $135 \cdot 00$ & $127.41,142.59$ & \\
\hline \multicolumn{7}{|c|}{ Experience of any controlling behaviour } \\
\hline No $(n 1757)$ & 75.00 & $66.90,83 \cdot 10$ & \multirow{2}{*}{0.06} & 120.00 & $114.01,125.99$ & \multirow{2}{*}{0.21} \\
\hline Yes (n 1038) & $60 \cdot 00$ & $52.46,67.54$ & & $135 \cdot 00$ & $128.42,141.58$ & \\
\hline
\end{tabular}

UHM, usual health message; BFC, breast-feeding counselling.

†Breast-feeding status was collected based on $15 \mathrm{~d}$ intervals

$\ddagger$ Comparison within each counselling stratum. $P$ values obtained from log rank tests. 
Table 3 Hazard ratio (HR) for likelihood of exclusive breast-feeding cessation at or before 6 months based on women's experience of domestic violence (DV) and counselling group in Matlab, Bangladesh ( $n$ 2795) $\dagger$

\begin{tabular}{|c|c|c|c|c|c|}
\hline \multirow[b]{2}{*}{ Women's experience of DV } & \multicolumn{2}{|c|}{ Unadjusted model } & \multicolumn{2}{|c|}{ Adjusted model $\ddagger$} & \multirow[b]{2}{*}{$P$ for interaction $\S$} \\
\hline & $\mathrm{HR}$ & $95 \% \mathrm{Cl}$ & $\mathrm{HR}$ & $95 \% \mathrm{Cl}$ & \\
\hline $\begin{array}{l}\text { No experience of any lifetime DV } \\
\text { Any lifetime DV ( } n \text { 1593) }\end{array}$ & \multicolumn{4}{|c|}{ Any lifetime DV ( $n$ 1593) } & \\
\hline UHM ( $n$ 824) & $1 \cdot 12^{*}$ & $1.01,1.25$ & $1 \cdot 13^{*}$ & $1.01,1.26$ & 0.05 \\
\hline $\mathrm{BFC}(n 769)$ & 0.97 & $0.86,1.08$ & 0.99 & $0.88,1.11$ & \\
\hline No experience of any physical DV & Ref. & Ref. & Ref. & Ref. & \\
\hline \multicolumn{6}{|l|}{ Any physical DV ( $n$ 597) } \\
\hline $\begin{array}{l}\text { UHM }(n 313) \\
\text { BFC }(n 284)\end{array}$ & $\begin{array}{l}0.97 \\
1.00\end{array}$ & $\begin{array}{l}0.87,1.10 \\
0.87,1.14\end{array}$ & $\begin{array}{l}0.98 \\
1.06\end{array}$ & $\begin{array}{l}0.86,1.12 \\
0.92,1.23\end{array}$ & 0.68 \\
\hline \multicolumn{5}{|l|}{ Any sexual DV ( $n$ 639) } & \\
\hline UHM (n 332) & $1 \cdot 14^{*}$ & $1.00,1.29$ & $1 \cdot 15^{\star}$ & $1.01,1.31$ & 0.08 \\
\hline $\mathrm{BFC}(n 307)^{\prime}$ & 1.00 & $0.87,1.14$ & 1.01 & $0.88,1.16$ & \\
\hline No experience of any emotional DV & Ref. & Ref. & Ref. & Ref. & \\
\hline \multicolumn{6}{|l|}{ Any emotional DV ( $n$ 766) } \\
\hline UHM (n 400) & 1.01 & $0.90,1.14$ & 1.02 & $0.91,1.15$ & 0.41 \\
\hline $\mathrm{BFC}(n 366)$ & $1 \cdot 10$ & $0.97,1.24$ & $1 \cdot 12$ & $0.99,1.27$ & \\
\hline \multicolumn{5}{|l|}{ Any controlling behaviour ( $n$ 1038) } & \\
\hline UHM ( $n$ 528) & $1 \cdot 10$ & $0.98,1.22$ & $1 \cdot 10$ & $0.99,1.23$ & 0.05 \\
\hline BFC $(n 510)$ & 0.94 & $0.84,1.05$ & 0.95 & $0.84,1.06$ & \\
\hline
\end{tabular}

UHM, usual health message; BFC, breast-feeding counselling; Ref., reference category.

${ }^{*} P<0.05$.

†HR and $95 \% \mathrm{Cl}$ were obtained from Cox regression analyses.

$\ddagger$ Models adjusted for maternal education, socio-economic status and BMI.

$\S P$ for interaction was obtained from models adjusted for maternal education, socio-economic status and BMI.

the counsellor and the mother, these elements of the intervention may have provided the support that enabled mothers to exclusively breast-feed for longer ${ }^{(24,39)}$. The assistance that was available at home during breastfeeding initiation may have supported optimal feeding practices such as proper latch and positioning, avoidance of pre-lacteal feeds and assistance with early breastfeeding challenges that then may have extended EBF duration $^{(18,40)}$. Additionally, the inclusion of key family members may have allowed more family support for mothers to follow recommended practices. Furthermore, the optimal number of counselling sessions across late pregnancy and early infancy for increasing duration of EBF is not known. The number of contacts in our study was sufficient to increase the duration of EBF and, importantly, did so among women who experienced DV. The number of contacts in the present study is close to what a woman may have with the maternal and infant health services.

In the present study, the result that counselling was particularly beneficial for lengthening the duration of EBF for those who experienced DV suggests that women who experience DV are vulnerable in terms of performing optimal health behaviours, but this can be overcome through specific interventions. DV has been shown to reduce self-efficacy for health-promoting behaviours ${ }^{(41-43)}$. Further, exposure to DV, especially controlling behaviour, could limit women's exposure to knowledge and support from family and friends. Breast-feeding counselling could extend the duration of EBF by strengthening self-efficacy, particularly benefiting those with low self-efficacy ${ }^{(44)}$, and may have also provided knowledge and support such that the exposure to DV was no longer associated with shorter EBF duration.

The current study had a relatively large sample size and was conducted in a population that is at risk for both DV and low rates of EBF at 6 months. The EBF counselling was warranted because of the low rates of EBF at 6 months, and because counselling increased the duration of $\mathrm{EBF}$ in previous studies. Women were randomly assigned to type of counselling intervention throughout the community, thereby eliminating selection bias. Women and counsellors were not blinded to the interventions, however, so it is possible that women in the BFC group would report longer EBF. There may have been exchange of breast-feeding knowledge from women in the BFC group to those in the UHM group, yet the BFC group still reported longer EBF duration. Self-reported EBF duration, however, was measured in this population by cross-validation using the ${ }^{2} \mathrm{H}$ dilution technique and found to be accurate ${ }^{(45)}$. The women who were lost to follow-up tended to be younger, with fewer children, less education and had delivered infants with lower birth weights than women who completed the study. The number and characteristics of the women who were lost to follow-up, however, were similar between the UHM and BFC groups, such that there were no differences in maternal and infant characteristics between the groups in the final sample. In our cohort, younger women and those with fewer children are less likely to experience DV, and those with fewer 
children exclusively breast-feed for a shorter period of time, so the loss to follow-up overall may have resulted in slightly higher prevalence of DV and longer durations of EBF in the entire sample. However, considering the relatively small proportion of women who had missing data or were lost to follow-up ( $<12 \%)$, it seems unlikely that selection bias would have influenced the reported outcomes to a large extent. Measuring recent violence may be an arguably more relevant indicator for current breastfeeding practices; however, exposure of lifetime violence may be more important given the long-lasting influence of DV on women's mental and physical health ${ }^{(3)}$. There could be residual confounding or other factors that are associated with the experience of DV that influences duration of EBF that we did not measure. Furthermore, the study results may be generalizable only to other populations in similar settings.

\section{Conclusions}

The experience of DV is common in this population as it is globally $^{(2)}$. Given DV poses a barrier to optimal breastfeeding practices, it could have a large impact on infant health with potential long-term public health implications. In populations where EBF for 6 months is crucial for infant health and survival, EBF counselling is of particular importance and may especially benefit women who are more vulnerable for early cessation of EBF due to exposure to DV.

\section{Acknowledgements}

Acknowledgements: The authors appreciate the support of the icddr,b staff where the research was conducted and are grateful to the women in the MINIMat study who gave their time to be interviewed. Financial support: The MINIMat research study was funded by icddr,b; UNICEF; the Swedish International Development Cooperation Agency (SIDA); the UK Medical Research Council; the Swedish Research Council; the UK Department for International Development (DFID); the Japan Society for the Promotion of Science; the Child Health and Nutrition Research Initiative (CHNRI); Uppsala University; and the US Agency for International Development (USAID). The funders had no role in study design, data collection and analysis, decision to publish, or preparation of the manuscript. Conflict of interest: The authors have no conflict of interest. Authorship: A.L.F. and S.Z. contributed equally to this work. A.L.F. and S.Z. performed statistical analyses, interpreted the data and drafted the manuscript. E.-C.E. contributed to MINIMat design, supervised the analyses, interpreted the data and contributed to manuscript revision. R.T.N. contributed to the design and supervision of the violence interviews, interpreted the data and contributed to manuscript revision. I.K. and A.I.K. contributed to the design of the breast-feeding counselling and supervision of the infant feeding data collection, and contributed to manuscript revision. All authors read and approved the final manuscript. Ethics of human subject participation: This study was conducted according to the guidelines laid down in the Declaration of Helsinki and all procedures involving human subjects were approved by the research and ethical review committee of icddr,b. Written informed consent was obtained from all subjects.

\section{References}

1. Flury M, Nyberg E \& Riecher-Rossler A (2010) Domestic violence against women: definitions, epidemiology, risk factors and consequences. Swiss Med Wkly 13, 23-27.

2. World Health Organization (2013) Global and Regional Estimates of Violence Against Women: Prevalence and Health Effects of Intimate Partner Violence and NonPartner Sexual Violence. Geneva: WHO.

3. Ellsberg M, Jansen HA, Heise L et al. (2008) Intimate partner violence and women's physical and mental health in the WHO multi-country study on women's health and domestic violence: an observational study. Lancet 371, $1165-1172$.

4. Yount KM, DiGirolamo AM \& Ramakrishnan U (2011) Impacts of domestic violence on child growth and nutrition: a conceptual review of the pathways of influence. Soc Sci Med 72, 1534-1554

5. World Health Organization \& UNICEF (2003) Global Strategy for Infant and Young Child Feeding. Geneva: WHO.

6. Arifeen S, Black RE, Antelman G et al. (2001) Exclusive breastfeeding reduces acute respiratory infection and diarrhea deaths among infants in Dhaka slums. Pediatrics 108, E67.

7. Sankar MJ, Sinha B, Chowdhury R et al. (2015) Optimal breastfeeding practices and infant and child mortality: a systematic review and meta-analysis. Acta Paediatr 104, 3-13.

8. Victora CG, Bahl R, Barros AJD et al. (2016) Breastfeeding in the 21st century: epidemiology, mechanisms, and lifelong effect. Lancet 387, 475-490.

9. Victora CG, Barros AJD, Fuchs SC et al. (2000) Effect of breastfeeding on infant and child mortality due to infectious diseases in less developed countries: a pooled analysis. Lancet 355, 451-455.

10. Misch ES \& Yount KM (2014) Intimate partner violence and breastfeeding in Africa. Matern Child Health $J$ 18, 688-697.

11. Moraes CL, de Oliveira AS, Reichenheim ME et al. (2011) Severe physical violence between intimate partners during pregnancy: a risk factor for early cessation of exclusive breast-feeding. Public Health Nutr 14, 2148-2155.

12. Zureick-Brown S, Lavilla K \& Yount KM (2015) Intimate partner violence and infant feeding practices in India: a cross-sectional study. Matern Child Nutr 11, 792-802.

13. Sorbo MF, Lukasse M, Brantsaeter AL et al. (2015) Past and recent abuse is associated with early cessation of breast feeding: results from a large prospective cohort in Norway. BMJ Open 5, e009240.

14. Chapman DJ, Morel K, Anderson AK et al. (2010) Breastfeeding peer counseling: from efficacy through scale-up. J Hum Lact 26, 314-326.

15. Haider R, Ashworth A, Kabir I et al. (2000) Effect of community-based peer counsellors on exclusive breastfeeding practices in Dhaka, Bangladesh: a randomised controlled trial. Lancet 356, 1643-1647. 
16. Kramer MS, Chalmers B, Hodnett ED et al. (2001) Promotion of breastfeeding intervention trial (PROBIT) - a randomized trial in the Republic of Belarus. JAMA 24, 413-420.

17. Sinha B, Chowdhury R, Sankar MJ et al. (2015) Interventions to improve breastfeeding outcomes: a systematic review and meta-analysis. Acta Paediatr 104, 114-135.

18. Morrow AL, Guerrero ML, Shults J et al. (1999) Efficacy of home-based peer counselling to promote exclusive breastfeeding: a randomised controlled trial. Lancet $\mathbf{3 5 3}$ 1226-1231.

19. Renfrew MJ, McCormick FM, Wade A et al. (2012) Support for healthy breastfeeding mothers with healthy term babies. Cochrane Database Syst Rev issue 5, CD001141.

20. Thomas JS, Yu EA, Tirmizi N et al. (2015) Maternal knowledge, attitudes and self-efficacy in relation to intention to exclusively breastfeed among pregnant women in rural Bangladesh. Matern Child Health 19, 49-57.

21. National Institute of Population Research and Training, Mitra and Associates \& Macro International (2009) Bangladesh Demographic and Health Survey 2007. Dhaka and Calverton, MD: NIPORT, Mitra and Associates, and Macro International.

22. National Institute of Population Research and Training, Mitra and Associates \& Macro International (2016) Bangladesh Demographic and Health Survey 2014. Dhaka and Rockville, MD: NIPORT, Mitra and Associates, and ICF International.

23. Persson LA, Arifeen S, Ekstrom EC et al. (2012) Effects of prenatal micronutrient and early food supplementation on maternal hemoglobin, birth weight, and infant mortality among children in Bangladesh: the MINIMat randomized trial. JAMA 16, 2050-2059.

24. Khan AI, Kabir I, Eneroth H et al. (2017) Effect of a randomised exclusive breastfeeding counselling intervention nested into the MINIMat prenatal nutrition trial in Bangladesh. Acta Paediatr 106, 49-54.

25. World Health Organization \& UNICEF (1993) Breastfeeding Counselling: A Training Course. Geneva: WHO.

26. Gwatkin DR, Rutstein S, Johnson K et al. (2000) SocioEconomic Differences in Health, Nutrition, and Population. Washington, DC: HNP/Poverty Thematic Group, World Bank.

27. Naved RT, Rimi NA, Jahan S et al. (2009) Paramedicconducted mental health counselling for abused women in rural Bangladesh: an evaluation from the perspective of participants. J Health Popul Nutr 27, 477-491.

28. Straus MA \& Douglas EM (2004) A short form of the Revised Conflict Tactics Scales, and typologies for severity and mutuality. Violence Vict 19, 507-520.

29. Antai D (2011) Controlling behavior, power relations within intimate relationships and intimate partner physical and sexual violence against women in Nigeria. BMC Public Health 29, 11.
30. Thompson RS, Bonomi AE, Anderson M et al. (2006) Intimate partner violence - prevalence, types, and chronicity in adult women. Am J Prev Med 30, 447-457.

31. de Sousa J, Burgess W \& Fanslow J (2014) Intimate partner violence and women's reproductive health. Obstet Gynaecol Reprod Med 14, 195-203.

32. Amar AF \& Gennaro S (2005) Dating violence in college women - associated physical injury, healthcare usage, and mental health symptoms. Nurs Res 54, 235-242.

33. Fisher J, Tran TD, Biggs B et al. (2013) Intimate partner violence and perinatal common mental disorders among women in rural Vietnam. Int Health 5, 29-37.

34. Ludermir AB, Schraiber LB, D'Oliveira AFPL et al. (2008) Violence against women by their intimate partner and common mental disorders. Soc Sci Med 66, 1008-1018.

35. Blyth RJ, Creedy DK, Dennis CL et al. (2004) Breastfeeding duration in an Australian population: the influence of modifiable antenatal factors. J Hum Lact 20, 30-38.

36. de Jager E, Skouteris H, Broadbent J et al. (2013) Psychosocial correlates of exclusive breastfeeding: a systematic review. Midwifery 29, 506-518.

37. Susiloretni KA, Hadi H, Prabandari YS et al. (2015) What works to improve duration of exclusive breastfeeding: lessons from the exclusive breastfeeding promotion program in rural Indonesia. Matern Child Health J 19, 1515-1525.

38. Bandura A (1977) Self-efficacy - toward a unifying theory of behavioral change. Psychol Rev 84, 191-215.

39. Hannula L, Kaunonen M \& Tarkka MT (2008) A systematic review of professional support interventions for breastfeeding. J Clin Nurs 17, 1132-1143.

40. Haroon S, Das JK, Salam RA et al. (2013) Breastfeeding promotion interventions and breastfeeding practices: a systematic review. BMC Public Health 13, Suppl. 3, S20.

41. Kang S \& Kim W (2011) A study of battered women's purpose of life and resilience in South Korea. Asian Soc Work Policy Rev 5, 145-159.

42. Matheson FI, Daoud N, Hamilton-Wright S et al. (2015) Where did she go? The transformation of self-esteem, selfidentity, and mental well-being among women who have experienced intimate partner violence. Womens Health Issues 25, 561-569.

43. Villegas N, Cianelli R, Gonzalez-Guarda R et al. (2013) Predictors of self-efficacy for HIV prevention among Hispanic women in South Florida. J Assoc Nurse Aids C 24, 27-37.

44. Srinivas GL, Benson M, Worley S et al. (2015) A clinic-based breastfeeding peer counselor intervention in an urban, lowincome population: interaction with breastfeeding attitude. J Hum Lact 31, 120-128.

45. Moore SE, Prentice AM, Coward WA et al. (2007) Use of stable-isotope techniques to validate infant feeding practices reported by Bangladeshi women receiving breastfeeding counseling. Am J Clin Nutr 85, 1075-1082. 